M. Grader, C. Eberle, P. Gerlinger, Large-Eddy Simulation and Analysis of a

Sooting Lifted Turbulent Jet Flame, Combustion and Flame 215 (2020) 458-470

The original publication is available at www.elsevier.com

https://doi.org/10.1016/j.combustflame.2020.01.042

(C2020 This manuscript version is made available under the CC-BY-NC-ND 4.0 license http://creativecommons.org/licenses/by-nc-nd/4.0/ 


\title{
Large-Eddy Simulation and Analysis of a Sooting Lifted Turbulent Jet Flame
}

\author{
Martin Grader ${ }^{a, *}$, Christian Eberle ${ }^{\mathrm{a}}$, Peter Gerlinger ${ }^{\mathrm{a}}$ \\ ${ }^{a}$ DLR - German Aerospace Center, Pfaffenwaldring, 38-40, 70659 Stuttgart, Germany
}

\section{Abstract}

A Large-Eddy Simulation (LES) is performed for a sooting, lifted, well characterized, non-premixed, turbulent jet flame. In order to accurately predict the lifted flame, a finite-rate chemistry model is used, which requires no assumptions concerning the combustion regime. Furthermore, feedback effects between all gaseous species and soot are captured inherently, by simultaneously solving the thermo-chemical state equations in a fully coupled way. Soot evolution is described by a sectional model, coupled to the gas phase by another sectional model for polycyclic aromatic hydrocarbons. The entire approach has already been comprehensively validated in premixed and non-premixed flames. The first aim of the present work is to extend the validation for LES. It is found that the simulated lift-off height and flame structure agree well with the measurements. A good prediction of soot evolution is achieved, which enables detailed investigations of soot formation and oxidation. Consequently, the second aim of the paper is to analyze the soot evolution by means of correlated statistics. It will be shown that the statistics depend on axial distance over the entire flame and on radial distance close to the base of the flame. These trends in temperature - soot volume fraction space can be attributed to the changing dominance of growth and oxidation of soot. Soot evolution is strongly affected by an oxygen leakage into the core of the flame caused by the flame lift-off. A combustion regime analysis reveals that the leakage leads to soot growth under premixed conditions, which causes the dependency of the correlated statistics on radial distance.

Keywords: Soot, Large-Eddy Simulation, Sectional soot model, Sooting lifted turbulent jet flame, Correlated soot statistics

\footnotetext{
${ }^{*}$ Corresponding author

Email address: martin.grader@dlr.de (Martin Grader)
} 


\section{Introduction}

In the context of growing environmental awareness and climate impact of combustion pollutants, soot emission control and reduction is a pressing need. The adverse impact of soot particles on human health [1] as well as its contribution to contrail formation in aviation [2] has been reported. Since contrails are known to impact the climate [3], reducing their prevalence by minimizing soot emissions [4] is desirable. Combustion simulation is on the way to becoming a development tool even with respect to pollutant reduction. Therefore, accurate models for soot prediction are an obvious necessity. This work aims to enhance the validation of a sectional soot model and to gain detailed insight into the soot evolution process. Sooting lifted turbulent flames are frequently encountered in technical applications, which makes soot model validation and soot evolution analysis essential in this regime.

Previous Large-Eddy Simulation (LES) of sooting jet flames mainly addressed attached flames [510] or bluff body stabilized flames [11, 12]. Various reasons lead to the choice of a lifted jet flame in this work: most technical flames are lifted, and the influence of numerical boundary condition uncertainties is lower compared to attached flames. Furthermore, a large set of validation data is available [13 16] for the chosen sooting lifted turbulent jet flame (SLTJF). However, lift-off height prediction in turbulent flames imposes high demands on flame models. This concern is met by using finite-rate chemistry, where transport equations are solved for each species of a relatively complex chemical mechanism. Flame lift-off also causes both premixed and non-premixed combustion regimes in the flame, affecting soot evolution. Therefore, extensive validation of the polycyclic aromatic hydrocarbons (PAHs) and soot model in premixed and non-premixed flames has been done in previous works [17 19]. It is self-evident that all model constants used in the previous validations remain unchanged in the current work.

In steady-state simulations of the SLTJF, a high sensitivity of soot formation to the correct prediction of fuel and air mixing is observed [15, 20,22]. This holds for other sooting jet flames, too. Thus, many authors use either a steady-state approach coupled to complex turbulence-chemistry interaction models like the transported probability density function (TPDF) method [23 25] or LES which resolves the large turbulent scales. The advantages of LES for soot prediction have already been demonstrated for semi-technical flames [26] being the reason for choosing this approach in the present paper.

Soot models can be classified by their representation of the particles size distribution (PSD). 
Monodisperse approaches [27, 28] or methods of moments [29] have not been able reproduce the PSD. Recent improvements are promising [30, 31], but to the authors' knowledge, they have not been applied to LES of jet flames yet. Methods capable of calculating the PSD, which have been applied to LES already, are particle tracking methods [32, 33] and sectional approaches [9, 18, 19]. For sooting turbulent jet flames, however, only the works of Rodrigues et al. [9] and Sewerin and Rigopoulos [33] use such elaborated techniques. They are complemented by the present work where a sectional soot model in combination with finite-rate chemistry is applied.

A great advantage of LES is the possibility of analyzing the resolved, correlated statistics. Experimental investigations of the SLTJF by Gu et al. [16] revealed a strong correlation between soot volume fraction $\left(f_{v}\right)$ and temperature $(T)$. Measurements in flames with similar fuels disagreed as to whether such a correlation exists [34] or not [35]. Several experimental studies of soot statistics (e.g., [36, 37]) and correlated soot statistics (e.g., 38 43]) have been published since. Comparison with these experimental results will be discussed during the analysis of the present LES results. 


\section{Modeling and numerical method}

\subsection{Filtered transport equations}

Along with the equations of mass, momentum and enthalpy transport, the reactive fluid is described by the equations of species transport. Applying a filtering to the set of equations, introducing filtered Reynolds $(\bar{\phi})$ and Favre $(\tilde{\phi})$ averages and using Einstein notation, the filtered species transport equation

$$
\frac{\partial \bar{\rho} \widetilde{Y}_{\alpha}}{\partial t}+\frac{\partial \bar{\rho} \widetilde{u}_{i} \tilde{Y}_{\alpha}}{\partial x_{i}}-\frac{\partial}{\partial x_{i}}\left[\left(\bar{\rho} D_{\alpha}+\frac{\mu_{t}}{S c_{t}}\right) \frac{\partial \widetilde{Y}_{\alpha}}{\partial x_{i}}\right]=\bar{\omega}_{\alpha}
$$

is obtained. Here, $u_{i}$ is the velocity component in $x_{i}$-direction, $\rho$ the density, $Y_{\alpha}$ and $D_{\alpha}$ are the mass fraction and molecular diffusion coefficient of species $\alpha$ respectively, and $\omega_{\alpha}$ is the chemical source term. The latter is calculated using finite-rate chemistry and Arrhenius type reaction rates. Details of the averaging process follow below. In the present LES, turbulent viscosity $\mu_{t}$ is determined by the WALE-model [44] and $S c_{t}=0.4$ is used for turbulent Schmidt-number [45]. Since thermophoretic transport of soot is unimportant in turbulent flames [46] and molecular diffusion of soot is negligible [47], molecular diffusion is considered for the gas phase species only. This gas phase diffusion is treated by a differential diffusion approach, which may be necessary for the accurate prediction of soot evolution [48, 49]. Heat radiation of $\mathrm{H}_{2} \mathrm{O}, \mathrm{CO}_{2}$, and soot is considered [18], assuming an optically thin gas.

\subsection{Turbulence-chemistry interaction}

Unresolved turbulence-chemistry interaction (TCI) causes unclosed moments of higher order in the averaged chemical source term $\bar{\omega}_{\alpha}$. Closure can be achieved by using probability density functions (PDF). In the present work, an efficient assumed PDF (APDF) approach [50, 51] is chosen, which assumes statistical independence of temperature, species, and soot fluctuations. In this way, filtered source terms are calculated by

$$
\bar{\omega}_{\alpha}=\iiint \omega_{\alpha}\left(T, \boldsymbol{Y}, \boldsymbol{Y}_{S}\right) P(T) P(\boldsymbol{Y}) P\left(\boldsymbol{Y}_{S}\right) \mathrm{d} T \mathrm{~d} \boldsymbol{Y} \mathrm{d} \boldsymbol{Y}_{S},
$$

where $T$ is the temperature while $\boldsymbol{Y}$ and $\boldsymbol{Y}_{S}$ are the vectors containing gas phase mass fractions and soot mass fractions, respectively. Subgrid scale variances required to determine the PDFs are calculated by means of a scale similarity approach (SSM) [52, 53] which is frequently found in LES [54, 55]. Furthermore, $P(T)$ is assumed to be clipped Gaussian, and $P(\boldsymbol{Y})$ a multivariate $\beta-\mathrm{PDF}$ [50]. Soot-turbulence interaction is described by a bimodal $\operatorname{PDF} P\left(\boldsymbol{Y}_{S}\right)$ [56], which consists 
of a sooting mode and a non-sooting mode. Applying the original formulation of Mueller and Pitsch [56] to the sectional soot model yields

$$
P\left(\boldsymbol{Y}_{s}\right)=\underbrace{a_{Y_{s}} \prod_{\alpha=\mathrm{SOOT}_{1}}^{\mathrm{SOOT}_{30}} \delta\left(Y_{s, \alpha}-Y_{s, \alpha}^{0}\right)}_{\text {non-sooting mode }}+\underbrace{b_{Y_{s}} \prod_{\alpha=\mathrm{SOOT}_{1}}^{\mathrm{SOOT}_{30}} \delta\left(Y_{s, \alpha}-Y_{s, \alpha}^{*}\right)}_{\text {sooting mode }} .
$$

The strength of the modes $\left(a_{Y_{s}}\right.$ and $\left.b_{Y_{s}}\right)$ and their respective positions $\left(Y_{s, \alpha}^{0}\right.$ and $\left.Y_{s, \alpha}^{*}\right)$ determine the shape of the PDF. These parameters are calculated from the normalization property and the first two moments of the PDF. Assuming $Y_{s, \alpha}^{0}=0$ [56] results in

$$
\begin{aligned}
& a_{Y_{s}}+b_{Y_{s}}=1 \\
& a_{Y_{s}} Y_{\mathrm{s}, \alpha}^{0}+b_{Y_{s}} Y_{\mathrm{s}, \alpha}^{*}=\widetilde{Y}_{\mathrm{s}, \alpha} \\
& a_{Y_{s}}\left(Y_{\mathrm{s}, \alpha}^{0}-\tilde{Y}_{\mathrm{s}, \alpha}\right)^{2}+b_{Y_{s}}\left(Y_{\mathrm{s}, \alpha}^{*}-\widetilde{Y}_{\mathrm{s}, \alpha}\right)^{2}=\widetilde{Y_{\mathrm{s}, \alpha}^{\prime \prime}{ }^{2}} \text {, with } \\
& \alpha=\mathrm{SOOT}_{1}, \ldots, \mathrm{SOOT}_{30} .
\end{aligned}
$$

In analogy to the gas phase TCI [50, 51], the sum of the soot section variances $\left(\sigma_{S}=\sum_{\alpha=\mathrm{SOOT}_{1}}^{\mathrm{SOOT}_{30}} \widetilde{Y_{\mathrm{s}, \alpha}^{\prime \prime}}\right)$ is used to parameterize the PDF. In this way, the unknown PDF parameters can be calculated from

$$
\begin{aligned}
a_{Y_{s}} & =1-b_{Y_{s}}, \\
Y_{\mathrm{s}, \alpha}^{*} & =\min \left\{\frac{\widetilde{Y}_{\mathrm{s}, \alpha}}{b_{Y_{s}}}, 1\right\} \text {, and } \\
b_{Y_{s}} & =\frac{\sum_{\alpha=\mathrm{SOOT}_{1}}^{\mathrm{SOOT}_{30}} \widetilde{Y}_{\mathrm{s}, \alpha}^{2}}{\sum_{\alpha=\mathrm{SOOT}_{1}}^{\mathrm{SOOT}_{30}} \widetilde{Y}_{\mathrm{s}, \alpha}^{2}+\sigma_{S}} .
\end{aligned}
$$

Decreasing subgrid scale fluctuations $\left(\lim \sigma_{S} \rightarrow 0\right)$ lead to $\lim Y_{\mathrm{s}, \alpha}^{*} \rightarrow \widetilde{Y}_{\mathrm{s}, \alpha}$, and the correct transition to laminar chemistry is achieved. As proposed in [56], soot-turbulence interaction is considered for $f_{v}>0.1 \mathrm{ppb}$ only. An advantage of the presented formulation is the possibility to calculate the required soot subgrid variance by the SSM approach; this avoids additional transport equations.

\subsection{Gas phase chemistry, PAH, and soot model}

Combustion chemistry and evolution of small soot precursors like benzene and toluene is described by a gas phase mechanism consisting of 43 species and 304 reactions. Validation has been performed for pyrolysis and combustion of short-chained hydrocarbons under atmospheric and pressurized conditions [57]. The mechanism is a reduced version of the detailed mechanism of Slavinskaya and Frank [58]. Its capabilities have been demonstrated in previous works [15, 17, 26, 59, 60]. 
Polycyclic aromatic hydrocarbons are modeled by a sectional approach developed by Eberle et al. [17] which is briefly described subsequently. Aromatic species with a molar mass between 100 and $800 \mathrm{~g} / \mathrm{mol}$ are lumped into logarithmically scaled sections as shown in Fig. 1. Three sections describe the evolution of PAHs and PAH radicals $\left(\mathrm{PAH}^{*}\right)$, respectively. The model includes PAH formation, growth and oxidation. Interaction between gas phase species and $\mathrm{PAH}_{1} / \mathrm{PAH}_{1}^{*}$ is described by 25 reversible reactions, derived from detailed reaction mechanisms [58, 61]. PAH growth is possible either by hydrogen abstraction carbon addition (HACA) [62], or by collisions with PAH*. Reaction coefficients of the latter are based on collision frequencies obtained from kinetic theory of gases, assuming a collision efficiency of unity. Furthermore, oxidation by $\mathrm{O}, \mathrm{OH}$ and $\mathrm{O}_{2}$ is taken into account. PAH collisions involving $\mathrm{PAH}_{3}$ or $\mathrm{PAH}_{3}^{*}$ lead to soot nucleation.

The sectional soot model used in this work has been developed by Blacha et al. [59] and was improved by Eberle et al. [18]. It is validated for a large range of operating conditions and flame regimes without changing its model constants [17, 18] and is used in this formulation in the present work. Figure 1 shows that the model considers 30 soot sections proceeding the PAH sections in terms of molecular mass. Soot density is assumed as $\rho_{S}=1800 \mathrm{~g} / \mathrm{mol}$ [63], leading to a diameter of nascent soot particles of $d_{\mathrm{SOOT}_{1}}=1.28 \mathrm{~nm}$. This is in good agreement with the measurements of Abid et al. 64. Primary soot particles which grow beyond a critical diameter agglomerate and form soot aggregates. This critical diameter is chosen to be $d_{\text {crit }}=14 \mathrm{~nm}$, which is in line with literature values that cover a range from 10 to $40 \mathrm{~nm}$ [65 67]. Transition from spherical soot particles to aggregates is modeled according to Kölyü et al. 68] and Rosner and Pyykönen [69]. Soot particle collisions and soot surface chemistry processes cause a change in the soot particles mass. Surface chemistry processes are subdivided into $\mathrm{PAH} / \mathrm{PAH}^{*}$ condensation, $\mathrm{C}_{2} \mathrm{H}_{2}$ addition, and oxidation by $\mathrm{OH}$ and $\mathrm{O}_{2}$. Corresponding stoichiometric coefficients are calculated according to Pope and Howard [70] in a way that both mass and atom conservation is maintained [59]. For a detailed description of the soot model the reader is referred to [18, 59].

\subsection{Numerical solver}

Simulations are conducted using the incompressible DLR in-house code THETA [71]. Time discretization is realized by the implicit Crank-Nicolson scheme and spatial discretization by central differencing. Thereby, second-order discretizations are achieved in time and space. A projection method [72] is used for pressure-velocity coupling. In total, 84 equations for pressure, momentum, enthalpy and species transport are solved. The latter two describe the thermochemical state of the 
fluid and are solved fully coupled. Hence, interaction between e.g. gas phase and soot is captured inherently, conserving mass and atoms. 


\section{Flame properties}

In the SLTJF experiment of Köhler et al. [13, 14, 15] the burner consists of a fuel nozzle for ethylene injection $(R e=10000)$ and a concentric cold laminar air co-flow. The lift-off height of the atmospheric flame is approximately eleven fuel nozzle diameters. In the following subsection, different phenomena which are characteristic for this flame are illustrated. A detailed description, the numerical setup, and the grid are given in the supplementary materials in SM1.

\subsection{Analysis of instantaneous data}

Figure 2 shows flow quantities and phenomena that influence soot evolution in the SLTJF either directly or indirectly. Length and time scales can vary significantly in jet flames. The impact on soot evolution is illustrated in Fig. 2a. Logarithmically scaled contours of the velocity magnitude $\left(v_{\text {mag }}\right)$ are overlaid by an iso-contour of soot volume fraction $\left(f_{v}\right)$. In regions of soot presence, the velocity magnitude has already decreased by one order of magnitude compared to fuel injection. This implies that soot evolution is governed by relatively large length and time scales which requires long sampling times to get reliable statistics. In the upstream part of the flame, soot is only present at the wings, whereas further downstream, soot is present in the entire flame region. Considering that soot formation relies on both increased temperature and fuel-rich conditions, Fig. 2p helps understand the soot distribution: only the core of the flame provides fuel-rich conditions, indicated by the iso-contour of the stoichiometric equivalence ratio $\Phi=1$. In the upstream part of the flame, high temperatures appear at the wings only. Further downstream, temperature rises on the flame centerline too, supporting soot formation and growth. This is not only due to mixing effects, but also due to heat release on the centerline. Figure 2 c shows that the flame lift-off causes an oxygen leakage into the core of the flame. Oxygen is observed at the axis up to $h \approx 150 \mathrm{~mm}$, where temperature rises and $\mathrm{O}_{2}$ is consumed by combustion. $\mathrm{OH}$ contours reveal, that maximum $\mathrm{OH}$ concentrations are found at the edges, as expected for a diffusion flame. A mean lift-off height of $22.0 \pm 1 \mathrm{~mm}$ is achieved by the LES, which is in excellent agreement with the measured lift-off height of $22.3 \pm 1.5 \mathrm{~mm}$ [15] (for further details see SM2). Oxygen leakage caused by flame lift-off does not only have an impact on heat release, but also on the combustion regime which in turn affects soot evolution. An estimation as to whether the local regime is premixed or non-premixed is given by the flame index (FI) [73, 74]. The flame index used in the present work is based on the 
gradients of oxidizer $\left(\mathrm{O}_{2}\right)$ and fuel $\left(\mathrm{C}_{2} \mathrm{H}_{4}\right)$ :

$$
\mathrm{FI}=\frac{\nabla \widetilde{\mathrm{Y}}_{\mathrm{O}_{2}} \nabla \widetilde{\mathrm{Y}}_{\mathrm{C}_{2} \mathrm{H}_{4}}}{\left|\nabla \widetilde{\mathrm{Y}}_{\mathrm{O}_{2}} \nabla \widetilde{\mathrm{Y}}_{\mathrm{C}_{2} \mathrm{H}_{4}}\right|} .
$$

Figure $2 \mathrm{~d}$ shows the combustion regimes in the reaction zone by weighting the FI with the absolute heat release rate $(|\dot{q}|)$. The flame exhibits a diffusion type flame-front at the edges and a premixed type reaction zone in the inner part. Heat release takes place at the edges of the diffusion flame and also in the core of the flame, caused by the described $\mathrm{O}_{2}$ leakage. Thereby, fuel and oxidizer are mixed prior to combustion and a premixed reaction zone is caused by the flame lift-off. Figure 20 estimates the implications of premixing on soot evolution. The iso-contour of $\Phi=1$ serves as a marker for the diffusive flame front. The filtered total soot source term $\bar{\omega}_{\text {soot }}=\sum_{\alpha=\text { SOOT1 }}^{\text {SOOT30 }} \bar{\omega}_{\alpha}$ highlights zones of dominant soot formation and growth (red) and oxidation (blue). Soot formation and growth take place in the inner part of the flame where premixed combustion dominates. Soot oxidation takes place close to the non-premixed reaction zone. Hence, soot evolution is influenced by both premixed and diffusive combustion regimes. A quantification will be given in section five. 


\section{Validation}

Drawing meaningful conclusions from LES results is only possible if the quality of the simulation is clear. The higher the numbers of quantities which can be compared to measurements, the better the quality of the simulation can be estimated. Since a comparatively large data-set of measurements is available for the current flame, a comprehensive validation has been performed and will be discussed in the following subsections. Note that the symmetry of the flame has been adopted for time-averaging radial profiles. Further validation of axial velocity, PAH and primary soot particle sizes can be found in SM3. An analysis of the grid quality can be found in SM4. Grid resolution is shown to be sufficient as correlated velocity structures are resolved by at least 10 grid cells in the flame [75].

\subsection{Flame stabilization}

Flame stabilization of the SLTJF is mainly driven by flame propagation. Hence, fluid dynamics preconditions for a correct lift-off height prediction by LES are a proper mixing of fuel and oxidizer as well as a correct prediction of the velocity field. Quantitative measurements of both have been obtained by Raman scattering measurements for ethylene mole fraction [15] and particle imaging velocimetry (PIV) for the velocity components close to injection [14] (partially published).

Figure 3 shows radial profiles of mean and root mean square (RMS) ethylene mole fraction $\left(X_{\mathrm{C}_{2} \mathrm{H}_{4}}\right)$ and axial velocity $\left(v_{x}\right)$ profiles at four heights above the burner. Since the flame stabilizes at $h=22.3 \mathrm{~mm}$, ethylene measurements in the flame-front at $h=25 \mathrm{~mm}$ are masked. The agreement between measured and simulated fuel profiles is very good for both mean and RMS values. Hence, the turbulent mixing of fuel and oxidizer is accurately described by the LES. Axial velocity data shows that the LES overestimates the mean values on the centerline and the RMS values at the wings, close to the injector. These minor differences decay further downstream. In contrast to the LES, where inflow values of the fuel jet are taken from periodic pipe calculations, the experiment features a nozzle at the inlet, which may explains the deviation in mean velocity. Difference in RMS velocity is expected to originate from the top-hat inflow profile of the cold co-flow. As both differences vanish quickly towards the anchor point of the flame, a correct lift-off height is predicted by the LES (see SM2). 


\subsection{Flame shape prediction}

Simulated temperature is compared to shifted-vibrational coherent anti-Stokes Raman scattering (SV-CARS) measurements of Köhler et al. [15] and to non-linear excitation regime two-line atomic fluorescence (nTLAF) measurements of Gu et al. [16]. All nTLAF data shown in this work is based on the assumption that temperatures below the detection limit of $800 \mathrm{~K}$ are equal to ambient temperature $\left(T=\left.300 \mathrm{~K}\right|_{T<800 \mathrm{~K}}\right)$ [16]. Consequently, nTLAF measurements indicate a lower limit for the mean temperature. Furthermore, nTLAF is limited to $\Phi>0.9$ [76], which may be violated at the wings of the flame.

Figure 4 shows good agreement between LES and SV-CARS axial mean and RMS temperature profiles. Small deviations between $150 \mathrm{~mm}<h<300 \mathrm{~mm}$ can be explained by the soot overprediction on the centerline, resulting in increased radiative heat losses. Even though maximum RMS values are higher in the measurements than in the LES, a good agreement is achieved here as well. Rising flame intermittency with rising $h$ is also predicted correctly. Only at $h<60 \mathrm{~mm}$ the RMS values rise slightly too early.

Figure 5 provides more detailed information by comparing radial temperature profiles, including nTLAF measurements. Both simulated and experimental maximum mean temperatures at $h=63 \mathrm{~mm}$ are located at the wings of the flame. Further downstream, the maximum temperatures of both are shifted towards the centerline, whereas the highest fluctuations are found at the wings of the flame. Besides a correct trend prediction by LES, also a good quantitative agreement between SV-CARS and LES is observed. On the other hand, the LES predicts a broader region of high temperatures than indicated by nTLAF. This difference can be explained by the rising intermittency towards the wings of the flame, causing $T<800 \mathrm{~K}$ and $\Phi<0.9$, restricting the nTLAF accuracy. However, at locations where the temperature starts to decrease, this explanation does not hold and a final conclusion about the flame shape prediction cannot be drawn by temperature comparison alone. Thus $\mathrm{OH}$, which is a good marker for hot regions on the lean side of the diffusion flame, is used as an additional indicator for the flame shape.

Figure 5 also compares mean and RMS radial profiles of simulated $\mathrm{OH}$ mole fraction $X_{\mathrm{OH}}$ and intensity measured by OH-planar laser-induced fluorescence (OH-PLIF) [15]. Since OH-PLIF results are not quantitative, normalized comparisons are made, using the corresponding maximum values of the entire field. Even though the OH-PLIF measurements exhibit slight asymmetries and a radial shift, the agreement with the LES results is remarkable. In contrast to temperature, the decrease of the mean $\mathrm{OH}$ concentration agrees well. Moreover, shape and magnitude of RMS profiles agree 
well between simulation and measurements, giving confidence in the predicted flame shape.

\subsection{Soot prediction}

Soot measurements in the investigated SLTJF have been performed by Köhler et al. [15] and $\mathrm{Gu}$ et al. [16] using laser-induced incandescence (LII). Figure 6 presents a comparison of mean and RMS soot volume fractions between LES and LII along the centerline of the flame. Differences in $f_{v, \max }$ are within a factor of two. Even for state of the art LES (e.g., [6, 8] 10, 12, 33]), this is an excellent result considering the wide range of flames for which the soot model is already validated. Furthermore, the shapes of the profiles from LES and LII agree very well. Taking the already described correct prediction of flame intermittency into account leads to the conclusion that the local relation between soot growth and oxidation is reproduced well by the simulation, even though the $f_{v}$ magnitude is too high. RMS values of $f_{v}$ agree very well both in trend and magnitude. However, due to the disagreement in mean soot volume fraction, a higher RMS value should be expected in the simulation.

Figure 7 compares mean and RMS radial $f_{v}$ profiles at five axial positions. Both LII datasets show the same trend of a narrow radial $f_{v}$ profile at $h=134 \mathrm{~mm}$, which is broadening further downstream. At the same time, the two-peak $f_{v}$ profile from $h=134 \mathrm{~mm}$ turns into a one-peak profile with maximum value on the centerline. This trend is reproduced by the LES. Consistently with the axial profiles shown in Fig. 6, the LES over-predicts $f_{v}$ on the centerline. However, the agreement towards the wings is excellent in shape and magnitude. Similar to the centerline profile, the radial RMS profiles of LES and measurements agree very well. The transfer from a two-peak into a single-peak profiles is also visible in the measured $f_{v}$-RMS profiles and confirmed by the LES. These results support the previous statement, that the soot model achieves good predictions in terms of position and shape of the profiles.

\subsection{Temperature statistics}

Soot evolution analysis in section 5 relies on joint statistics of temperature and soot volume fraction. As temperature statistics have been measured by SV-CARS [15], their validation helps to understand the capabilities of the LES and partially the reliability of the simulated joint statistics.

Figure 8 compares simulated and measured temperature histograms at four positions along the centerline. The number of events included in the statistic is 565000 for the LES and between 914 and 1189 for the measurements. Due to this this difference, normalized histograms are plotted, 
which can be interpreted like a PDF. At $h=50 \mathrm{~mm}$, close to the anchor point of the flame, the shapes of the histograms agree very well. The most probable temperature is $T_{\mathrm{mp}} \approx 500 \mathrm{~K}$ and events with $T>750 \mathrm{~K}$ are rarely observed and do not occur for $T>1200 \mathrm{~K}$. LES results are shifted slightly towards higher temperatures. In the zone of incipient soot nucleation and growth at $h=100 \mathrm{~mm}$, a perfect agreement between LES and SV-CARS is found both in shape and magnitude of the histograms. Close to the position with maximum $f_{v \text {,mean }}$, at $h=250 \mathrm{~mm}$, the LES results are shifted towards lower temperatures. This is caused by a soot over-prediction and subsequent to large radiative heat losses. Nevertheless, the shape is in acceptable agreement. In the downstream part of the flame $(h=350 \mathrm{~mm})$, where soot evolution is affected both by oxidation and intermittency, a correct prediction of the temperature statistics is indispensable. Despite the absence of events with $T>2100 \mathrm{~K}$ in the LES due to heat losses, the agreement is very good. Both in measurements and LES two areas of almost equally distributed $T$ frequencies are found between $500<T<1500 \mathrm{~K}$ and $1500<T<2000 \mathrm{~K}$, respectively. This behavior underlines the intermittency in this part of the flame and the ability of the LES to reproduce it. In conclusion, temperature statistics on the centerline, close to maximum $f_{v \text {,mean }}$, are slightly affected by an overprediction of $f_{v}$ which causes a decrease of $T_{\mathrm{mp}}$. At the other locations, a remarkable agreement in temperature statistics between simulation and experiment is observed. These results give confidence in the analysis of joint $T$ - $f_{v}$-statistics, provided in the next section. 


\section{Analysis of soot evolution}

Correlated statistics of soot and related quantities have been used to advance the understanding of soot evolution in turbulent flames both by measurements (e.g., [38 43]) and simulations (e.g., [7, 24, 47, 77, 78]). Such correlated statistics have also been measured in the investigated SLTJF by $\mathrm{Gu}$ et al. [16]. Comparison to the LES results is not only necessary for validation, but is also an opportunity to enhance the insight into soot evolution by making use of the extensive LES data-set. First, however, the LES post-processing methodology is described. Then, the agreement between measured and simulated joint statistics of temperature and soot volume fraction is discussed. Next, possible explanations for the observed behavior of the statistics are given by means of soot source term analysis. Finally, the analysis is completed by further distinguishing between premixed and non-premixed combustion regimes.

\subsection{Methodology}

$\mathrm{Gu}$ et al. [16] measured correlated soot statistics at three radial positions and five heights above the burner. The radial positions are defined by the width of the soot field $W$, which is adopted in this work as $W=\left.r\right|_{\left\langle f_{v}\right\rangle=0.15 \cdot \max \left(\left\langle f_{v}\right\rangle\right)}$. Since the qualitative $f_{v}$ trend is reproduced by the LES, the axial positions are chosen identical to the experiment. Measured statistics have been sampled in an area of $5 \times 3 \mathrm{~mm}^{2}$ (radial $\times$ axial), and resolved by pixel arrays of $0.33 \times 0.33 \mathrm{~mm}^{2}$, which is similar to the grid resolution of the LES. In order to reduce statistical noise, the axis-symmetry of the flame is used and LES statistics are sampled in circumferential direction on a cross-section that corresponds to the measurement area. To achieve statistical independence, a rather low sampling rate of $200 \mathrm{~Hz}$ is chosen, corresponding to at least one flow through time through each sampling volume $\left(V_{\text {sample }}\right)$. For plotting two-variable statistics, the $T$ - $f_{v}$-space $\left(s\left(T, f_{v}\right)\right)$ is subdivided in $N_{T}=N_{f_{v}}=50$ temperature and soot volume fraction sections $\left(k\left(T, f_{v}\right)\right)$, respectively. In accordance to the measurements, $s\left(T, f_{v}\right)$ covers a temperature range of $1200 \mathrm{~K} \leq T \leq 2400 \mathrm{~K}$ and a $f_{v}$-range of $0.002 \mathrm{ppm} \leq f_{v} \leq 5 \mathrm{ppm}$. To ensure that the maximum values of the statistics correspond to the most probable values, statistics are presented as joint histograms rather than as marginal-PDFs with the frequency in one $T$ - $f_{v}$-section $k$ defined as

$$
\text { Frequency }(k)=\left.\sum_{t=1}^{N_{\text {tstep }}} \sum_{i=1}^{N_{\text {cells }}} v_{\text {cell }_{i}}^{*} D_{i, t}\right|_{k\left(T, f_{v}\right)} .
$$

Here $N_{\text {tsteps }}$ is the number of LES timesteps used for sampling the statistics, and $N_{\text {cells }}$ the number

of cells in $V_{\text {sample. }}$ The indices $t$ and $i$ correspond to a timestep or a cell, respectively. The impact of 
varying grid sizes on the statistics in $V_{\text {sample }}$ is taken into account by weighting with the normalized cell volume $\left(v_{\text {cell }_{i}}^{*}=v_{\text {cell }_{i}} / \max \left(\left.v_{\text {cell }}\right|_{\text {sample }_{\text {e }}}\right)\right)$. The occurrence of a statistical event $D_{i, t}$ conditioned on one $T$ - $f_{v}$-section $k$ reads

$$
\left.D_{i, t}\right|_{k\left(T, f_{v}\right)}= \begin{cases}1, & f_{v, \mathrm{LL}(k)}<f_{v_{i, t}} \leq f_{v, \mathrm{UL}(k)} \cap T_{\mathrm{LL}(k)}<T_{i, t} \leq T_{\mathrm{UL}(k)} \\ 0, & \text { otherwise }\end{cases}
$$

where the subscripts $\mathrm{LL}(k)$ and $\mathrm{UL}(k)$ denote the lower limit and upper limit respectively of one $T$ - $f_{v}$-section. Further investigations include conditioned statistics to distinguish events of dominant soot growth

$$
\text { Frequency }\left.(k)\right|_{\text {growth }}=\left.\sum_{t=1}^{N_{\text {tsteps }}} \sum_{i=1}^{N_{\text {cells }}} v_{\text {cell }_{i}}^{*} D_{i, t}\right|_{k\left(T, f_{v}\right), \omega_{s_{i, t}}>0}
$$

and soot oxidation (Frequency $\left.(k)\right|_{\text {ox }}$ ), which is calculated likewise assuming $\left.D_{i, t}\right|_{k\left(T, f_{v}\right), \omega_{s_{i, t}}<0}$. Furthermore events in premixed combustion regime (pre) and non-premixed combustion regime (nonpre) are obtained by further conditioning on FI $>1$ (see Eq. (10) ) and FI $<1$, respectively. The soot source term

$$
\omega_{s_{i, t}}=\sum_{\alpha=\mathrm{SOOT}_{1}}^{\mathrm{SOOT}_{30}} \bar{\omega}_{\alpha_{i, t}}
$$

represents the sum of the filtered soot source terms of the sectional soot model. Note that frequencies are represented by contour lines, smoothed in $T$ - $f_{v}$-space to minimize statistical noise. Contour lines are plotted for 35\% and $70 \%$ of the maximum frequency. For the frequencies in pseudo color, however, no smoothing is applied and one pixel corresponds to one $T$ - $f_{v}$-section. The following discussion also includes the mean soot source term

$$
\left\langle\omega_{s}\right\rangle=\left\langle\left.\frac{1}{V_{\text {sample }}} \sum_{i=1}^{N_{\text {cells }}} v_{\text {cell }_{i}} \omega_{s_{i, t}}\right|_{s\left(T, f_{v}\right)}\right\rangle
$$

in the $T$ - $f_{v}$-space $s\left(T, f_{v}\right)$, weighted by the cell volume. Time-averaging is denoted by $\langle\cdot\rangle$. As for Eq. (13), the growth and oxidation conditioned derivative will be used as well. In order to asses the importance of the premixed regimes for soot evolution, a soot source term weighted FI conditioned ratio

$$
\left.\mathrm{r}_{\text {pre }}\right|_{\text {growth }}=\frac{1}{\left\langle\left.\omega_{s}\right|_{\text {growth }}\right\rangle}\left\langle\left.\frac{1}{V_{\text {sample }}} \sum_{i=1}^{N_{\text {cells }}} v_{\text {cell }_{i}} \omega_{s_{i, t}}\right|_{s\left(T, f_{v}\right), \omega_{s_{i, t}}>0, \mathrm{FI}>0}\right\rangle
$$

is defined for soot growth conditioned statistics. A corresponding ratio can also be defined for oxidation dominated statistics $\left(\left.\mathrm{r}_{\text {pre }}\right|_{\text {ox }}\right.$ ) assuming $\left.\omega_{s_{i, t}}\right|_{s\left(T, f_{v}\right), \omega_{s_{i, t}}<0, \mathrm{FI}>0}$. The importance of nonpremixed combustion regimes is hence $\mathrm{r}_{\text {non-pre }}=1-\mathrm{r}_{\text {pre }}$. 


\subsection{Joint statistics of temperature and soot}

Figure 9 presents joint $T$ - $f_{v}$-histograms at five different heights above the burner and three widths of the soot field ( $W=0 \%, 50 \%$ and $90 \%$ ), respectively. Contour lines are drawn for $T-f_{v^{-}}$ statistics conditioned on growth (red lines) and oxidation (blue lines). Moreover, the mean soot source term $\left\langle\omega_{s}\right\rangle$ (see Eq. (15)) is given for each position. In the following discussion, firstly $T$ - $f_{v^{-}}$ statistics are described and subsequently compared between LES and relevant measurements. Next, spatial dependencies of the statistics are analyzed by taking soot growth and oxidation conditioned statistics into account. Finally, conclusions drawn from the analysis are connected to measurement results.

At the most upstream centerline sampling position $(h=134 \mathrm{~mm}, W=0 \%)$ soot is found in the LES in a very small region around $T=1400 \mathrm{~K}$ and $0.1 \mathrm{ppm}<f_{v}<1 \mathrm{ppm}$. In radial direction, this region gets broader in $T$-space at $W=50 \%$, but most probable values are still found for $T=1400 \mathrm{~K}$. At $W=90 \%$, which is close to the flame front, the distribution is different. High probabilities for $0.1 \mathrm{ppm}<f_{v}<1 \mathrm{ppm}$ are observed in a large region of $1500 \mathrm{~K}<T<1900 \mathrm{~K}$. Moreover, events with lower $f_{v}$ and $2000 \mathrm{~K}<T<2200 \mathrm{~K}$ are found to be equally probable. Hence, statistics at this most upstream location are dependent on radial distance. With increasing height above the burner up to $h=310 \mathrm{~mm}$, the centerline region of high probability ( $W=0 \%$ ) is shifted moderately towards higher temperatures and soot volume fractions. This axial dependency of the statistics can also be observed at $W=50 \%$, which reflects the evolution of mean $T$ and $f_{v}$ values. Close to the flame front, at $W=90 \%$, higher soot volume fractions become more probable with increasing height above the burner at $T<1800 \mathrm{~K}$. Likewise, the probability for low $f_{v}$ values at high temperatures decreases. Moreover, the maximum occurring temperature decreases, narrowing the distribution in both $T$ and $f_{v}$ space. At $h=310 \mathrm{~mm}$, events with $f_{v}<0.02 \mathrm{ppm}$ become moderately probable over the whole temperature range. Finally, at the most downstream location $(h=374 \mathrm{~mm})$, the joint histograms are similar irrespective of their radial position. The dependency on radial distance, observed at $h=134 \mathrm{~mm}$, is no longer present. Hence, there is a dependency on axial distance in the statistics.

The shape of the profiles differ significantly between measurements [16] (not shown in this work) and simulation, even though temperature statistics are predicted very well by LES (see Fig. 8). As discussed before, this is attributed to different representations and uncertainties in modeling and measurements. Therefore, trends and similarities are compared. As found by Gu et al. [16], correlation between $T$ and $f_{v}$ can be observed at all positions. Furthermore, experiment and LES agree that 
at the lower part of the flame a strong dependence on radial position exists. At the most downstream position, the radial dependency vanishes, which again is in agreement with the measurements. Consequently, the LES distributions depend on axial distance as found in measurements [16, 40] as well. Maximum LES values of $f_{v}$ are always located between $1400 \mathrm{~K}<T<1700 \mathrm{~K}$, which is well within the range observed in measurements that extends over $1350 \mathrm{~K}<T<1750 \mathrm{~K}$ [16, 35, 38, 40, 42]. Also the measured trend that the most probable $f_{v}$ shifts towards higher temperatures with increasing height above the burner [16] is reproduced well by the soot model. Centerline measurements of Shaddix and Zhang [38] reveal that distributions of $T$ and $f_{v}$ widen with increasing $h$. This holds for the LES results, too. In conclusion, trends found in the simulation are also observed in experiments, justifying further analysis.

In Fig. 9 the mean soot source term $\left\langle\omega_{s}\right\rangle$ is given at each sampling location. It shows that soot formation and growth $\left(\left\langle\omega_{s}\right\rangle>0\right)$ is dominant at the center upstream part while oxidation $\left(\left\langle\omega_{s}\right\rangle<0\right)$ dominates positions downstream and away from the centerline. Furthermore, spatial dependencies observed in the $T-f_{v}$-statistics are found in $\left\langle\omega_{s}\right\rangle$ as well: close to the injector, a strong production of soot takes place at $W=0 \%$ and $W=50 \%$, which decrease radially towards $W=90 \%$. In axial direction, this trend extenuates until source terms are similar in radial direction at $h=374 \mathrm{~mm}$. Consequently, also a dependency of soot source term magnitude on axial direction is found: as $h$ increases, $\left\langle\omega_{s}\right\rangle$ decreases. Due to identical spatial dependencies of $T$ - $f_{v}$-statistics and $\left\langle\omega_{s}\right\rangle$, it is suspected that an explanation of the statistical trends can be found by further analyzing $\left\langle\omega_{\mathrm{s}}\right\rangle$. This is done by separating events of dominant soot growth (dotted red lines, see Eq. (13) ) from events of dominant soot oxidation (dashed blue lines). Oxidation is prevailing at $T>1800 \mathrm{~K}$, whereas growth is dominating at $T<1800 \mathrm{~K}$. In oxidation-dominated parts of the $T$ - $f_{v}$-space, $f_{v}$ spreads over several orders of magnitude, whereas in growth-dominated regions, $f_{v}$ is found mostly within one order of magnitude. Regions of growth or oxidation dominance nearly maintain their positions in $T-f_{v}$-space, respectively. Consequently, changes in $\left\langle\omega_{s}\right\rangle$ necessarily lead to changes of the frequency distribution in $T$ - $f_{v}$-space. Hence, the strong dependence of probability on radial position at the bottom of the flame is a result of the high change in $\left\langle\omega_{s}\right\rangle$. The reason for this change is discussed in the next section, taking premixing by $\mathrm{O}_{2}$ leakage into the core of the flame into account.

$\mathrm{Gu}$ et al. [16] argue that an increase of the most probable value of $T$ is linked to an increasing probability of soot oxidation due to high temperature. This can be confirmed by the LES analysis. As most probable values of the joint statistic shift towards higher temperatures, they enter the 
oxidation dominated parts of the $T$ - $f_{v}$-space which are particularly found close to the flame front at $W=90 \%$ at the most upstream position. Qamar et al. [37] observed that soot decrease results from the complete burnout of some soot sheets rather than a reduction of $f_{v}$ in all soot filaments. This finding has been confirmed by LES of Mueller et al. [6] and is observed at $h=374 \mathrm{~mm}$ in the present SLTJF as well. Even though $f_{v \text {,mean }}$ is lower than $0.4 \mathrm{ppm}$ in this position, the joint statistics reveal that events with $f_{v}>1 \mathrm{ppm}$, connected to soot growth, are still frequently observed. Moreover, events of $f_{v}<0.1 \mathrm{ppm}$ are likely, causing the intermittency. As will be shown in Fig. 11, the latter ones are governed by soot oxidation and are part of the burnout described in [37]. Lee et al. [36] concluded for their experimentally investigated turbulent attached diffusion jet flame that the relation between soot and temperature is associated with soot production and destruction rates. This is confirmed by the present analysis of the SLTJF.

\subsection{Effects of premixing on the joint statistics of temperature and soot}

Even though the SLTJF is a diffusion flame, lift-off causes a significant $\mathrm{O}_{2}$ leakage into the core of the flame and heat release is found in premixed regions as well, as shown in Fig. 2, How this phenomena affects soot evolution is of particular interest, because soot evolution strongly depends on the combustion regime. As many flame models depend on the combustion regime as well, this analysis may be important also for model development or for choosing the right model in case of lifted flames. In the following analysis, the combustion regimes are separated by the flame index introduced in Eq. (10). Thereby, joint histograms of event probability, conditioned on either soot growth or oxidation, are shown in Fig. 10 and Fig. 11 in $T$ - $f_{v}$-space, respectively. Dotted red iso-lines depict statistics of premixed flame regions and dashed blue iso-lines depict statistics of diffusive flame regions. To support the analysis, $\left\langle\omega_{s}\right\rangle$ (see Eq. (15)) and $\mathrm{r}_{\text {pre }}$ (see Eq. (16)) are given for each position with the respective conditioning.

Figure 10 shows the analysis of the growth-dominated $T$ - $f_{v}$-statistics. In contrast to the unconditioned statistics presented in Fig. 9, the dependency on radial position is only weak at the upstream part of the flame and vanishes completely further downstream. At most positions, regions of diffusive and premixed growth coincide. Soot growth, indicated by the conditioned soot source term $\left\langle\left.\omega_{s}\right|_{\text {growth }}\right\rangle$, is almost equally strong at all radial locations at $h=134 \mathrm{~mm}$. Further downstream, the source term magnitude decreases first at the wings, and downstream of $h=264 \mathrm{~mm}$ also on the centerline. Hence, strong soot growth predominantly takes place at the centerline and the bottom part until close to the flame wings. The parameter $\left.r_{\text {pre }}\right|_{\text {growth }}$ (see Eq. (16)) reveals that 
premixed soot evolution is of major importance at the upstream part of the flame where growth is strongest. On the centerline, soot growth takes place almost exclusively under premixed conditions. At $h=374 \mathrm{~mm}$, where any radial dependence of the statistics is hardly visible, non-premixed and premixed events for soot growth are equally likely. However, soot growth is not dominating at this position any more (see $\left\langle\omega_{s}\right\rangle$ in Fig. 9). The radial dependency of the statistics observed at the bottom of the flame, especially in Fig. 9, is in contrast to the measurements of Mahmoud et al. [40]. This difference is likely caused by partial premixing on the centerline due to $\mathrm{O}_{2}$ leakage, which has not been reported in the experimentally investigated attached diffusive jet flame [40]. Thereby, soot growth does not depend on fuel-air mixing by large-scale-fluctuations only. As shown in Fig. 10, premixing effects on soot growth decrease in downstream direction. Likewise, the weak differences in radial direction completely vanish. This supports the assumption that the radial dependency of statistics is an effect of premixing caused by the flame lift-off. However, the strong radial dependency of $T$ - $f_{v}$-statistics can not be completely explained by growth conditioned statistics.

Figure 11 presents joint $T$ - $f_{v}$-histograms for events dominated by oxidation. Dashed blue lines and dotted red lines indicate statistics of non-premixed and premixed combustion regimes, respectively. Soot oxidation is most likely to be found at $T>1800 \mathrm{~K}$ and causes $f_{v}$ to be distributed over several orders of magnitude. No dependence of the shape of the joint histograms on $\left\langle\left.\omega_{s}\right|_{\text {ox }}\right\rangle$ can be found. Unlike soot growth conditioned statistics, premixed and non-premixed combustion regimes can be found at different locations in $T$ - $f_{v}$-space. Close to the primary injector $(h \leq 210 \mathrm{~mm})$ and at the centerline, premixed and non-premixed zones almost coincide in $T$ - $f_{v}$-space. Further downstream, oxidation in diffusive regimes is limited to $T>1800 \mathrm{~K}$ and $f_{v}<1 \mathrm{ppm}$, whereas oxidation in premixed regimes takes place over the whole temperature range $(T<2200 \mathrm{~K})$ and $f_{v}<0.1 \mathrm{ppm}$. The former is caused by soot oxidation in the diffusive flame-front, which is indicated by the restriction to relatively high temperatures. The latter is caused by partially oxidized soot which is transported through the flame front and mixed with cold co-flowing air. Thereby temperature decreases but oxidation is still active due to oxygen excess and sufficiently high temperatures. Similar observations in experiments have been reported by Shaddix and Zhang [38], who found signs for soot being present in quenched vortices, and Kruse et al. [41] who found soot clusters on the lean side of the flame. The ratio $\left.\mathrm{r}_{\text {pre }}\right|_{\mathrm{ox}}$ indicates that soot oxidation occurs predominantly in the non-premixed combustion regime. Due to the soot transport through the flame front and subsequent mixing, this ratio rises slightly. However, $\left.\mathrm{r}_{\text {pre }}\right|_{\mathrm{ox}}$ is still low, revealing that oxidation of quenched soot pockets is weak. An exception is the most upstream point on the centerline $(h=134 \mathrm{~mm}, W=0 \%)$, where 
oxidation takes place nearly exclusively in the premixed combustion regime. Since soot growth dominates at this position, it is suspected that insufficient turbulent fuel-air mixing prevents more oxidation events. It may be concluded that even though oxidation in the non-premixed regime dominates, premixed oxidation can not be neglected since soot burnout is affected. As for unconditioned $T$ - $f_{v}$-statistics, a radial dependency is found at the most upstream location $(h=134 \mathrm{~mm})$, too. Especially the oxidation conditioned soot source term $\left\langle\left.\omega_{s}\right|_{\text {ox }}\right\rangle$ differs by more than one order of magnitude, indicating strong oxidation towards the wings of the flame. Thereby an explanation of the radial dependency can be given: $\mathrm{O}_{2}$ leakage into the core of the flame promotes almost equally strong soot growth over the radius. However, oxidation is strongest on the wings of the flame. Since the locations of soot growth and oxidation dominated statistics are fixed in $T$ - $f_{v}$-space, the effect of changing soot source terms is a radial dependence of $T$ - $f_{v}$-statistics. 


\section{Conclusion}

In this work, a sooting, lifted, turbulent jet flame is simulated by LES. Thereby, validation of a sectional soot model is extended. A good to excellent agreement with experimental data is achieved. In addition, the LES data-set is exploited to get insight into soot evolution by analyzing joint statistics of temperature and soot volume fraction. It is demonstrated that high fidelity soot simulations based on extensively tested models can produce reliable results; these support experimental investigations to achieve a better understanding of soot evolution in turbulent jet flames.

Grid resolution is shown to be sufficient as correlated velocity structures are resolved by at least ten grid cells in the flame. Analysis of the instantaneous flame structure revealed that lift-off causes oxygen leakage into the core of the flame, resulting in locally premixed combustion. Comparison of time-averaged results with measurements showed an excellent agreement of axial velocity and ethylene mole fraction close to the fuel injector, resulting in an excellent prediction of the lift-off height by LES. Prediction of axial velocity, temperature, $\mathrm{OH}$ and $\mathrm{PAH}$ in most parts of the flame is within measurement uncertainties, giving confidence in the modeling framework and the flame shape prediction. Deviations of centerline temperatures arise from over-prediction of soot volume fraction by a factor of two. This is comparable or even better than similar LES of sooting jet flames. Despite the soot over-prediction on the centerline, the axial and radial shape of $f_{v}$ field is matched very well. Hence, soot growth and oxidation are predicted at the correct positions in the flame. Joint $T$ - $f_{v}$-statistics show similar trends in LES and measurements. In the lower part of the flame, statistics exhibited a clear trend in radial direction, which ceases further downstream. Due to the good overall prediction by LES, the results are used for a more comprehensive analysis.

It is shown that soot growth and oxidation are found at nearly constant positions in $T$ - $f_{v}$-space, irrespective of the sampling position in the flame. Hence, trends in $T$ - $f_{v}$-statistics can be attributed to the changing local dominance of growth and oxidation. Further conditioning of the statistics on the combustion regime reveals that soot growth happens predominantly in the premixed regime, caused by oxygen leakage into the core of the flame. Only far downstream, where intermittency is high and oxidation dominates, soot growth also occurs in the non-premixed regime. In turn, soot oxidation takes place primarily in the non-premixed regime. As exceptions, two different events causing premixed oxidation are identified: one, as soot is transported through the flame front and mixed with co-flowing air, and another, caused by oxygen leakage in the upstream centerline part 
of the flame. Both are of minor importance for the overall soot oxidation, but the local importance can not be ruled out. Flame lift-off and the oxygen leakage also explain the dependency of $T$ - $f_{v^{-}}$ statistics on radial distance, which is in contrast to correlated measurements in attached turbulent diffusion jet flames. In conclusion, both soot and combustion model applied to lifted flames in future simulations are recommended to be validated in both premixed and non-premixed regimes.

\section{Acknowledgements}

The authors thank F. Eigentler, Y. Emmi, Dr. A. Fiolitakis, Dr. K. P. Geigle and Dr. M. Köhler

for their contribution to this work. We would also like to thank Prof. G. J. Nathan for providing experimental data. The authors gratefully acknowledge the Gauss Centre for Supercomputing e.V. (www.gauss-centre.eu) for funding this project by providing computing time on the GCS Supercomputer SuperMUC at Leibniz Supercomputing Centre (LRZ, www.lrz.de). 


\section{References}

[1] I. M. Kennedy, The health effects of combustion-generated aerosols, Proc. Combust. Inst. 31 (2007) 2757-2770.

[2] E. J. Jensen, O. B. Toon, The potential impact of soot particles from aircraft exhaust on cirrus clouds, Geophys. Res. Lett. 24 (1997) 249-252.

[3] D. J. Travis, A. M. Carleton, R. G. Lauritsen, Climatology: Contrails reduce daily temperature range, Nature 418 (2002) 601-601.

[4] U. Burkhardt, L. Bock, A. Bier, Mitigating the contrail cirrus climate impact by reducing aircraft soot number emissions, npj Clim. Atmos. Sci. 1 (2018) 37.

[5] H. El-Asrag, S. Menon, Large eddy simulation of soot formation in a turbulent non-premixed jet flame, Combust. Flame 156 (2009) 385-395.

[6] M. E. Mueller, H. Pitsch, LES model for sooting turbulent nonpremixed flames, Combust. Flame 159 (2012) 2166-2180.

[7] P. Donde, V. Raman, M. E. Mueller, H. Pitsch, Les/pdf based modeling of soot-turbulence interactions in turbulent flames, Proc. Combust. Inst. 34 (2013) 1183-1192.

[8] Y. Xuan, G. Blanquart, Effects of aromatic chemistry-turbulence interactions on soot formation in a turbulent non-premixed flame, Proc. Combust. Inst. 35 (2015) 1911-1919.

[9] P. Rodrigues, B. Franzelli, R. Vicquelin, O. Gicquel, N. Darabiha, Coupling an LES approach and a soot sectional model for the study of sooting turbulent non-premixed flames, Combust. Flame 190 (2018) 477-499.

[10] S. Yang, J. K. Lew, M. E. Mueller, Large eddy simulation of soot evolution in turbulent reacting flows: Presumed subfilter PDF model for soot-turbulence-chemistry interactions, Combust. Flame 209 (2019) 200-213.

[11] M. E. Mueller, Q. N. Chan, N. H. Qamar, B. B. Dally, H. Pitsch, Z. T. Alwahabi, G. J. Nathan, Experimental and computational study of soot evolution in a turbulent nonpremixed bluff body ethylene flame, Combust. Flame 160 (2013) 1298-1309. 
[12] S. Deng, M. E. Mueller, Q. N. Chan, N. H. Qamar, B. B. Dally, Z. T. Alwahabi, G. J. Nathan, Hydrodynamic and chemical effects of hydrogen addition on soot evolution in turbulent nonpremixed bluff body ethylene flames, Proc. Combust. Inst. 36 (2017) 807-814.

[13] M. Köhler, I. Boxx, K. P. Geigle, W. Meier, Simultaneous planar measurements of soot structure and velocity fields in a turbulent lifted jet flame at $3 \mathrm{kHz}$, Appl. Phys. B 103 (2011) $271-279$.

[14] M. Köhler, K. P. Geigle, W. Meier, B. M. Crosland, K. A. Thomson, G. J. Smallwood, Sooting turbulent jet flame: characterization and quantitative soot measurements, Appl. Phys. B 104 (2011) 409-425.

[15] M. Köhler, K.-P. Geigle, T. Blacha, P. Gerlinger, W. Meier, Experimental characterization and numerical simulation of a sooting lifted turbulent jet diffusion flame, Combust. Flame 159 (2012) 2620-2635.

[16] D. Gu, Z. Sun, B. B. Dally, P. R. Medwell, Z. T. Alwahabi, G. J. Nathan, Simultaneous measurements of gas temperature, soot volume fraction and primary particle diameter in a sooting lifted turbulent ethylene/air non-premixed flame, Combust. Flame 179 (2017) 33-50.

[17] C. Eberle, P. Gerlinger, M. Aigner, A sectional PAH model with reversible PAH chemistry for CFD soot simulations, Combust. Flame 179 (2017) 63-73.

[18] C. Eberle, P. Gerlinger, M. Aigner, Large-eddy simulations of a sooting lifted turbulent jetflame, Proceedings of the Fifty-Fith AIAA Aerospace Sciences Meeting (2017) AIAA 20171785 .

[19] M. Grader, C. Eberle, P. Gerlinger, M. Aigner, LES of a pressurized, sooting aero-engine model combustor at different equivalence ratios with a sectional approach for PAHs and soot, Proceedings of ASME Turbo Expo (2018) GT2018-75254.

[20] M. Yen, V. Magi, J. Abraham, Modeling soot formation in turbulent jet flames at atmospheric and high-pressure conditions, Energy \& Fuels 32 (2018) 8857-8867.

[21] M. R. Busupally, A. De, Numerical modeling of soot formation in a turbulent c2h4/air diffusion flame, Int. J. Spray Combust. Dyn. 8 (2016) 67-85. 
[22] R. Saini, A. De, Assessment of soot formation models in lifted ethylene/air turbulent diffusion flame, Therm. Sci. Eng. Prog. 3 (2017) 49-61.

[23] J. Consalvi, F. Nmira, Transported scalar PDF modeling of oxygen-enriched turbulent jet diffusion flames: Soot production and radiative heat transfer, Fuel 178 (2016) 37-48.

[24] M. A. Schiener, R. P. Lindstedt, Joint-scalar transported PDF modelling of soot in a turbulent non-premixed natural gas flame, Combust. Theory Model. 22 (2018) 1134-1175.

[25] T. Dittmann, A. Fiolitakis, P. M. Gerlinger, M. Aigner, Simulation of a piloted turbulent sooting jet-flame using a transported-PDF and a sectional soot modeling approach, Proceedings of the AIAA Scitech 2019 Forum (2019) AIAA 2019-0445.

[26] C. Eberle, P. Gerlinger, K. P. Geigle, M. Aigner, Toward finite-rate chemistry large-eddy simulations of sooting swirl flames, Combust. Sci. Technol. 190 (2018) 1194-1217.

[27] K. Leung, R. Lindstedt, W. Jones, A simplified reaction mechanism for soot formation in nonpremixed flames, Combust. Flame 87 (1991) 289-305.

[28] B. Zamuner, F. Dupoirieux, Numerical simulation of soot formation in a turbulent flame with a monte-carlo pdf approach and detailed chemistry, Combust. Sci. Technol. 158 (2000) 407-438.

[29] M. Mueller, G. Blanquart, H. Pitsch, Hybrid method of moments for modeling soot formation and growth, Combust. Flame 156 (2009) 1143-1155.

[30] B. Franzelli, A. Vié, N. Darabiha, A three-equation model for the prediction of soot emissions in LES of gas turbines, Proc. Combust. Inst. 37 (2019) 5411-5419.

[31] S. Salenbauch, M. Sirignano, M. Pollack, A. D’Anna, C. Hasse, Detailed modeling of soot particle formation and comparison to optical diagnostics and size distribution measurements in premixed flames using a method of moments, Fuel 222 (2018) 287-293.

[32] L. Gallen, A. Felden, E. Riber, B. Cuenot, Lagrangian tracking of soot particles in LES of gas turbines, Proc. Combust. Inst. 37 (2019) 5429-5436.

[33] F. Sewerin, S. Rigopoulos, An LES-PBE-PDF approach for predicting the soot particle size distribution in turbulent flames, Combust. Flame 189 (2018) 62-76. 
[34] Y. Sivathanu, G. Faeth, Temperature / soot volume fraction correlations in the fuel-rich region of buoyant turbulent diffusion flames, Combust. Flame 81 (1990) 150-165.

[35] A. Coppalle, D. Joyeux, Temperature and soot volume fraction in turbulent diffusion flames: Measurements of mean and fluctuating values, Combust. Flame 96 (1994) 275-285.

[36] S.-Y. Lee, S. R. Turns, R. J. Santoro, Measurements of soot, oh, and pah concentrations in turbulent ethylene/air jet flames, Combust. Flame 156 (2009) 2264-2275.

[37] N. Qamar, Z. Alwahabi, Q. Chan, G. Nathan, D. Roekaerts, K. King, Soot volume fraction in a piloted turbulent jet non-premixed flame of natural gas, Combust. Flame 156 (2009) $1339-1347$.

[38] C. R. Shaddix, J. Zhang, Joint temperature-volume fraction statistics of soot in turbulent non-premixed jet flames, Proceedings of the eighth US Combustion Meeting (2013) Paper 070LT-0100.

[39] V. Narayanaswamy, N. Clemens, Simultaneous LII and PIV measurements in the soot formation region of turbulent non-premixed jet flames, Proc. Combust. Inst. 34 (2013) 1455-1463.

[40] S. Mahmoud, G. Nathan, P. Medwell, B. Dally, Z. Alwahabi, Simultaneous planar measurements of temperature and soot volume fraction in a turbulent non-premixed jet flame, Proc. Combust. Inst. 35 (2015) 1931-1938.

[41] S. Kruse, J. Ye, Z. Sun, A. Attili, B. Dally, P. Medwell, H. Pitsch, Experimental investigation of soot evolution in a turbulent non-premixed prevaporized toluene flame, Proc. Combust. Inst. 37 (2019) 849-857.

[42] O. Park, R. A. Burns, O. R. Buxton, N. T. Clemens, Mixture fraction, soot volume fraction, and velocity imaging in the soot-inception region of a turbulent non-premixed jet flame, Proc. Combust. Inst. 36 (2017) 899-907.

[43] B. Franzelli, P. Scouflaire, S. Candel, Time-resolved spatial patterns and interactions of soot, $\mathrm{PAH}$ and $\mathrm{OH}$ in a turbulent diffusion flame, Proc. Combust. Inst. 35 (2015) 1921-1929.

[44] F. Nicoud, F. Ducros, Subgrid-scale stress modelling based on the square of the velocity gradient tensor, Flow, Turbul. Combust. 62 (1999) 183-200. 
[45] H. Pitsch, H. Steiner, Large-eddy simulation of a turbulent piloted methane/air diffusion flame (sandia flame d), Phys. Fluids 12 (2000) 2541.

[46] D. O. Lignell, J. H. Chen, P. J. Smith, Three-dimensional direct numerical simulation of soot formation and transport in a temporally evolving nonpremixed ethylene jet flame, Combust. Flame 155 (2008) 316-333.

[47] F. Bisetti, G. Blanquart, M. E. Mueller, H. Pitsch, On the formation and early evolution of soot in turbulent nonpremixed flames, Combust. Flame 159 (2012) 317-335.

[48] A. Kronenburg, R. Bilger, J. Kent, Modeling soot formation in turbulent methane-air jet diffusion flames, Combust. Flame 121 (2000) 24-40.

[49] A. Attili, F. Bisetti, M. E. Mueller, H. Pitsch, Formation, growth, and transport of soot in a three-dimensional turbulent non-premixed jet flame, Combust. Flame 161 (2014) 1849-1865.

[50] S. S. Girimaji, Assumed $\beta$-pdf model for turbulent mixing: Validation and extension to multiple scalar mixing, Combust. Sci. Technol. 78 (1991) 177-196.

[51] P. Gerlinger, Investigation of an assumed pdf approach for finite-rate chemistry, Combust. Sci. Technol. 175 (2003) 841-872.

[52] J. Bardina, J. Ferziger, W. Reynolds, Improved subgrid-scale models for large-eddy simulation, Proceedings of the thirteenth Fluid and Plasma Dynamics Conference (1980) AIAA 1980-1357.

[53] A. W. Cook, J. J. Riley, A subgrid model for equilibrium chemistry in turbulent flows, Phys. Fluids 6 (1994) 2868-2870.

[54] H. Wang, N. Qin, M. Sun, H. Wu, Z. Wang, A hybrid LES (large eddy simulation)/assumed sub-grid PDF (probability density function) model for supersonic turbulent combustion, Sci. China Technol. Sci. 54 (2011) 2694.

[55] A. Kempf, R. Lindstedt, J. Janicka, Large-eddy simulation of a bluff-body stabilized nonpremixed flame, Combust. Flame 144 (2006) 170-189.

[56] M. E. Mueller, H. Pitsch, Large eddy simulation subfilter modeling of soot-turbulence interactions, Phys. Fluids 23 (2011) 115104. 
[57] N. Slavinskaya, O. Haidn, Reduced chemical model for high presure methane combustion with PAH formation, Proceedings of the fourty-sixth AIAA Aerospace Sciences Meeting and Exhibit (2008) AIAA 2008-1012.

[58] N. Slavinskaya, P. Frank, A modelling study of aromatic soot precursors formation in laminar methane and ethene flames, Combust. Flame 156 (2009) 1705-1722.

[59] T. Blacha, M. Di Domenico, P. Gerlinger, M. Aigner, Soot predictions in premixed and nonpremixed laminar flames using a sectional approach for PAHs and soot, Combust. Flame 159 (2012) 181-193.

[60] C. Eberle, P. Gerlinger, K. P. Geigle, M. Aigner, Numerical investigation of transient soot evolution processes in an aero-engine model combustor, Combust. Sci. Technol. 187 (2015) $1841-1866$.

[61] N. A. Slavinskaya, U. Riedel, S. B. Dworkin, M. J. Thomson, Detailed numerical modeling of pah formation and growth in non-premixed ethylene and ethane flames, Combust. Flame 159 (2012) 979-995.

[62] M. Frenklach, H. Wang, Detailed mechanism and modeling of soot particle formation, in: H. Bockhorn (Ed.), Soot Formation in Combustion, Springer Berlin Heidelberg, 1994, pp. $165-192$.

[63] H. Richter, S. Granata, W. H. Green, J. B. Howard, Detailed modeling of pah and soot formation in a laminar premixed benzene/oxygen/argon low-pressure flame, Proc. Combust. Inst. 30 (2005) 1397-1405.

[64] A. Abid, E. Tolmachoff, D. Phares, H. Wang, Y. Liu, A. Laskin, Size distribution and morphology of nascent soot in premixed ethylene flames with and without benzene doping, Proc. Combust. Inst. 32 (2009) 681-688.

[65] C. Saggese, S. Ferrario, J. Camacho, A. Cuoci, A. Frassoldati, E. Ranzi, H. Wang, T. Faravelli, Kinetic modeling of particle size distribution of soot in a premixed burner-stabilized stagnation ethylene flame, Combust. Flame 162 (2015) 3356-3369.

[66] J. Bhatt, R. Lindstedt, Analysis of the impact of agglomeration and surface chemistry models on soot formation and oxidation, Proc. Combust. Inst. 32 (2009) 713-720. 
[67] M. Smooke, M. Long, B. Connelly, M. Colket, R. Hall, Soot formation in laminar diffusion flames, Combust. Flame 143 (2005) 613-628.

[68] U. Köylü, Y. Xing, D. E. Rosner, Fractal morphology analysis of combustion-generated aggregates using angular light scattering and electron microscope images, Langmuir 11 (1995) 4848-4854.

[69] D. E. Rosner, J. J. Pyykönen, Bivariate moment simulation of coagulating and sintering nanoparticles in flames, AIChE J. 48 (2002) 476-491.

[70] C. J. Pope, J. B. Howard, Simultaneous particle and molecule modeling (SPAMM): An approach for combining sectional aerosol equations and elementary gas-phase reactions, Aerosol Sci. Technol. 27 (1997) 73-94.

[71] M. Di Domenico, P. Gerlinger, M. Aigner, Development and validation of a new soot formation model for gas turbine combustor simulations, Combust. Flame 157 (2010) 246-258.

[72] A. J. Chorin, Numerical solution of the navier-stokes equations, Math. Comput. 22 (1968) $745-745$.

[73] H. Yamashita, M. Shimada, T. Takeno, A numerical study on flame stability at the transition point of jet diffusion flames, Symp. (Int.) Combust. 26 (1996) 27-34.

[74] P. Domingo, L. Vervisch, K. Bray, Partially premixed flamelets in LES of nonpremixed turbulent combustion, Combust. Theory Model. 6 (2002) 529-551.

[75] L. Davidson, Large eddy simulations: How to evaluate resolution, Int. J. Heat Fluid Flow 30 (2009) 1016-1025.

[76] G. Nathan, P. Kalt, Z. Alwahabi, B. Dally, P. Medwell, Q. Chan, Recent advances in the measurement of strongly radiating, turbulent reacting flows, Prog. Energy Combust. Sci. 38 (2012) 41-61.

[77] D. O. Lignell, J. H. Chen, P. J. Smith, T. Lu, C. K. Law, The effect of flame structure on soot formation and transport in turbulent nonpremixed flames using direct numerical simulation, Combust. Flame 151 (2007) 2-28. 
[78] A. Attili, F. Bisetti, M. E. Mueller, H. Pitsch, Damköhler number effects on soot formation and growth in turbulent nonpremixed flames, Proc. Combust. Inst. 35 (2015) 1215-1223. 


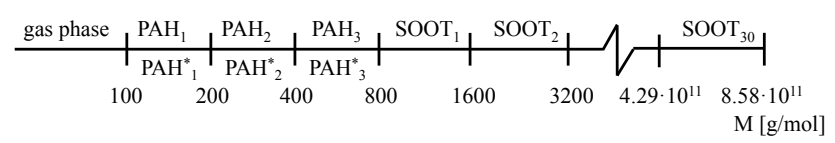

Figure 1: Definition of the PAH, $\mathrm{PAH}^{*}$, and soot sections [17].
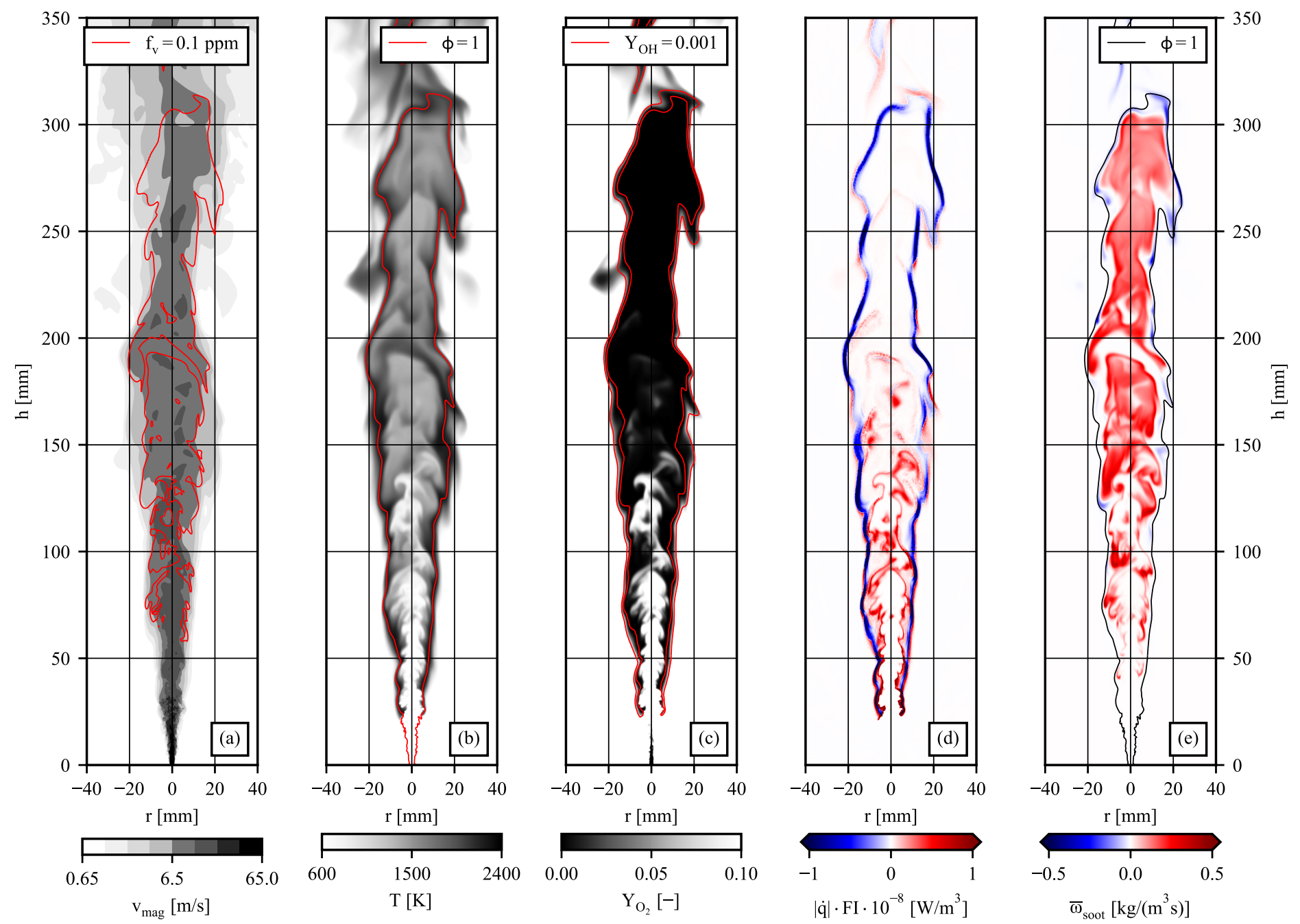

Figure 2: Contour plots of instantaneous flame and soot properties in a cut through the centerline. 

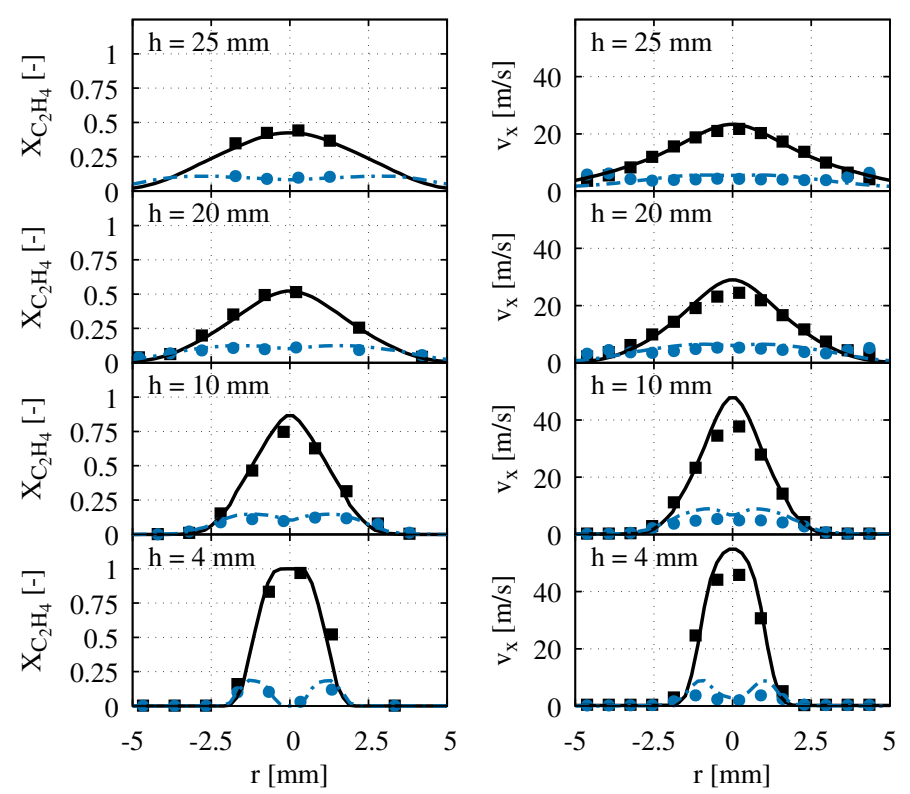

Figure 3: Radial profiles of ethylene mole fraction $X_{\mathrm{C}_{2} \mathrm{H}_{4}}$ (left) and axial velocity $v_{x}$ (right), mean ( $\longrightarrow$ simulation; - experiment [15]) and RMS ( -... simulation; - experiment [15). For a better readability, not every velocity measurement point is shown.
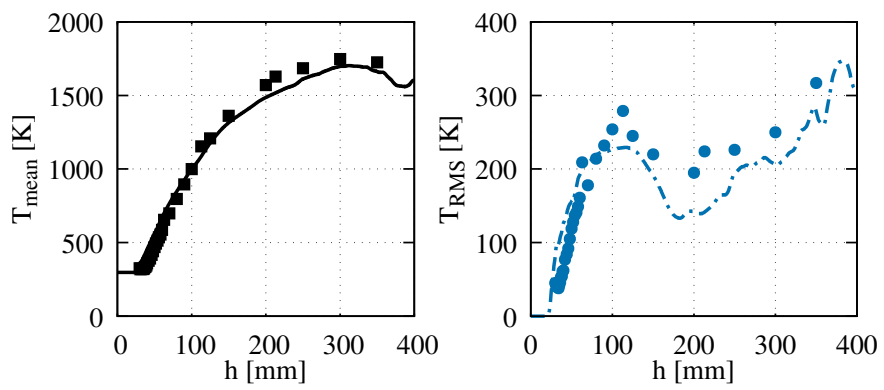

Figure 4: Axial profiles of temperature $T$, mean (left) and RMS (right). Lines refer to LES and symbols to measurements [15]. 

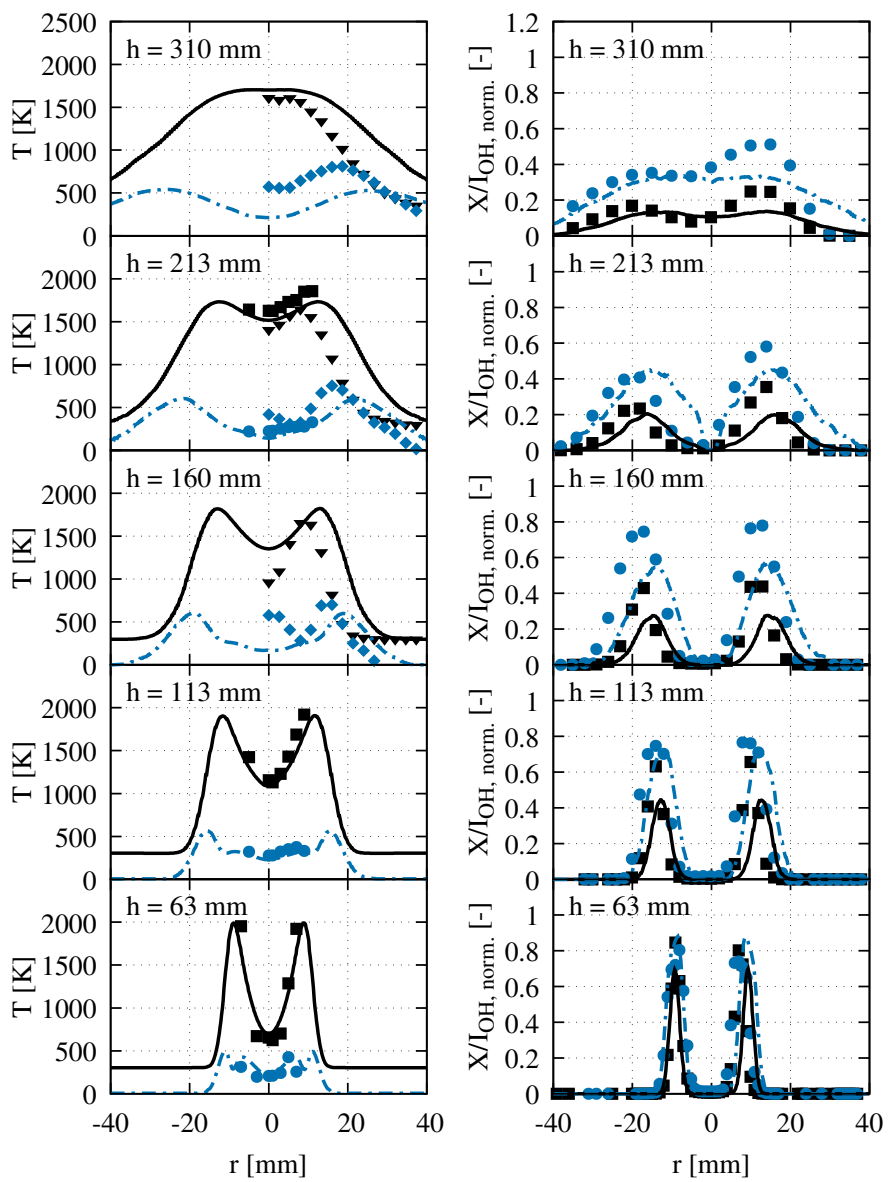

Figure 5: Radial profiles of temperature $T$ (left), normalized $\mathrm{OH}$ signal intensity $I$, and mole fraction $X_{\mathrm{OH}}$ (right), mean ( - simulation; $\boldsymbol{\square}$ experiment [15; $\boldsymbol{\nabla}$ experiment [16] ) and RMS ( -... simulation; • experiment [15; - experiment [16]). For a better readability, not every measurement point is shown.
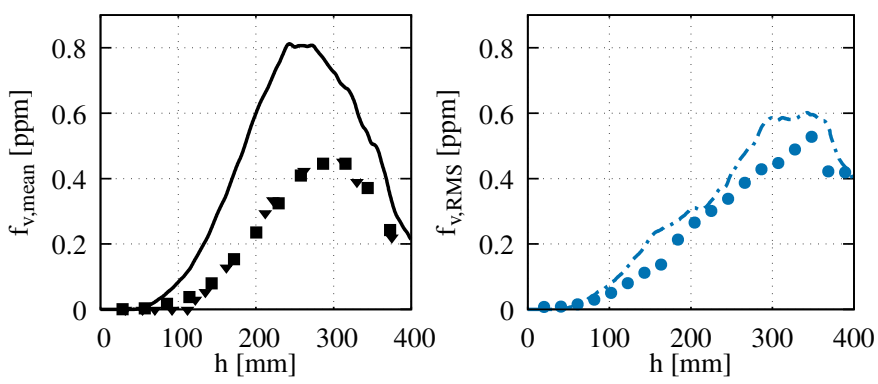

Figure 6: Axial profiles of soot volume fraction $f_{v}$, mean (left) and RMS (right). Lines refer to LES and symbols to measurements ( $\mathbf{\square}$ experiment [15]; $\mathbf{\nabla}$ experiment [16]). For a better readability, not every measurement point is shown. 


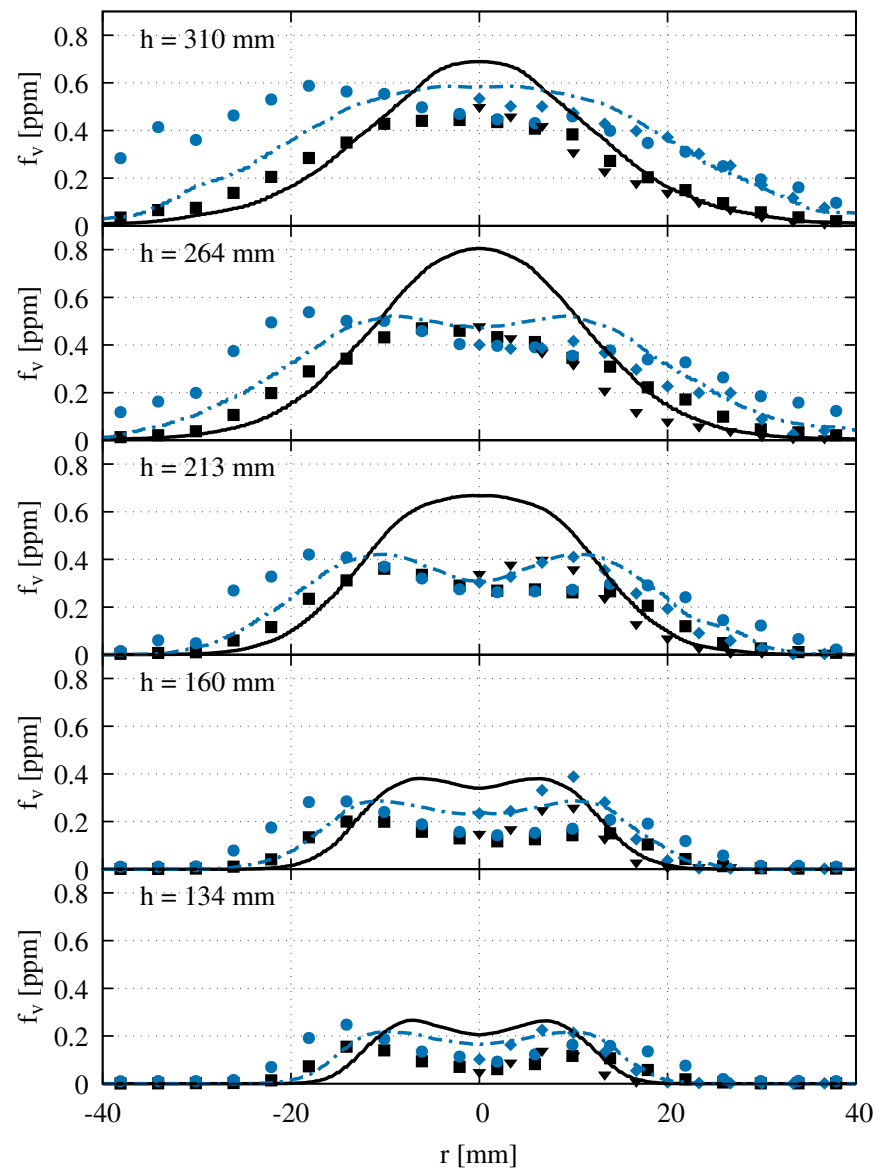

Figure 7: Radial profiles of soot volume fraction $f_{v}$, mean ( $\longrightarrow$ simulation; $\boldsymbol{\square}$ experiment [15]; $\mathbf{\nabla}$ experiment [16] ) and RMS ( -... simulation; $\bullet$ experiment [15]; $\bullet$ experiment [16]). For a better readability, not every measurement point is shown. 


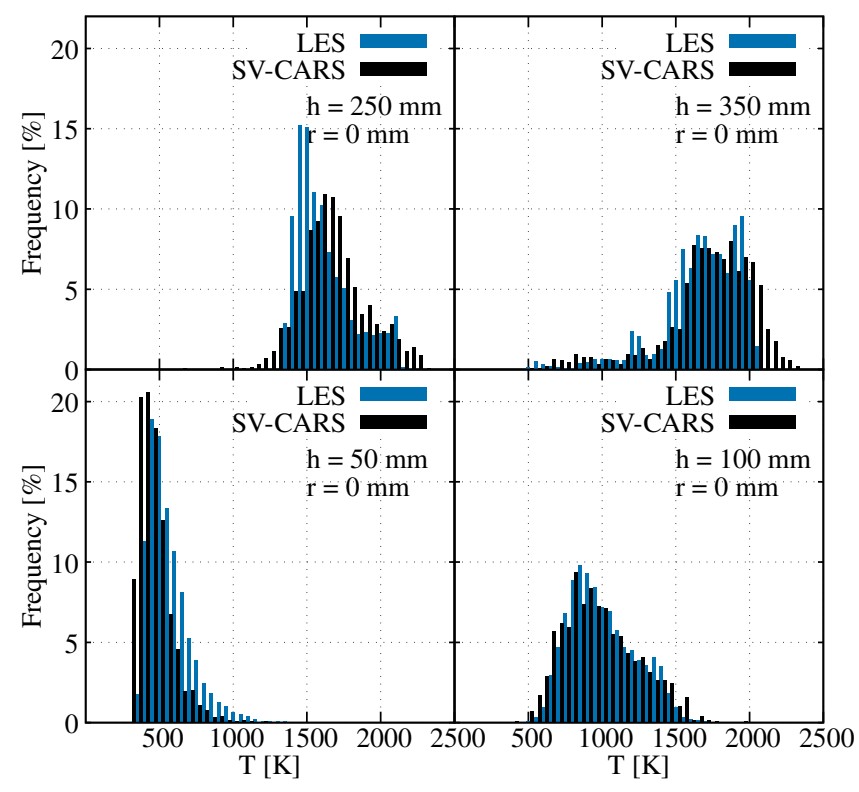

Figure 8: Normalized temperature histograms on the centerline at four heights above the burner $h$. LES results in blue and SV-CARS measurements [15] in black. 

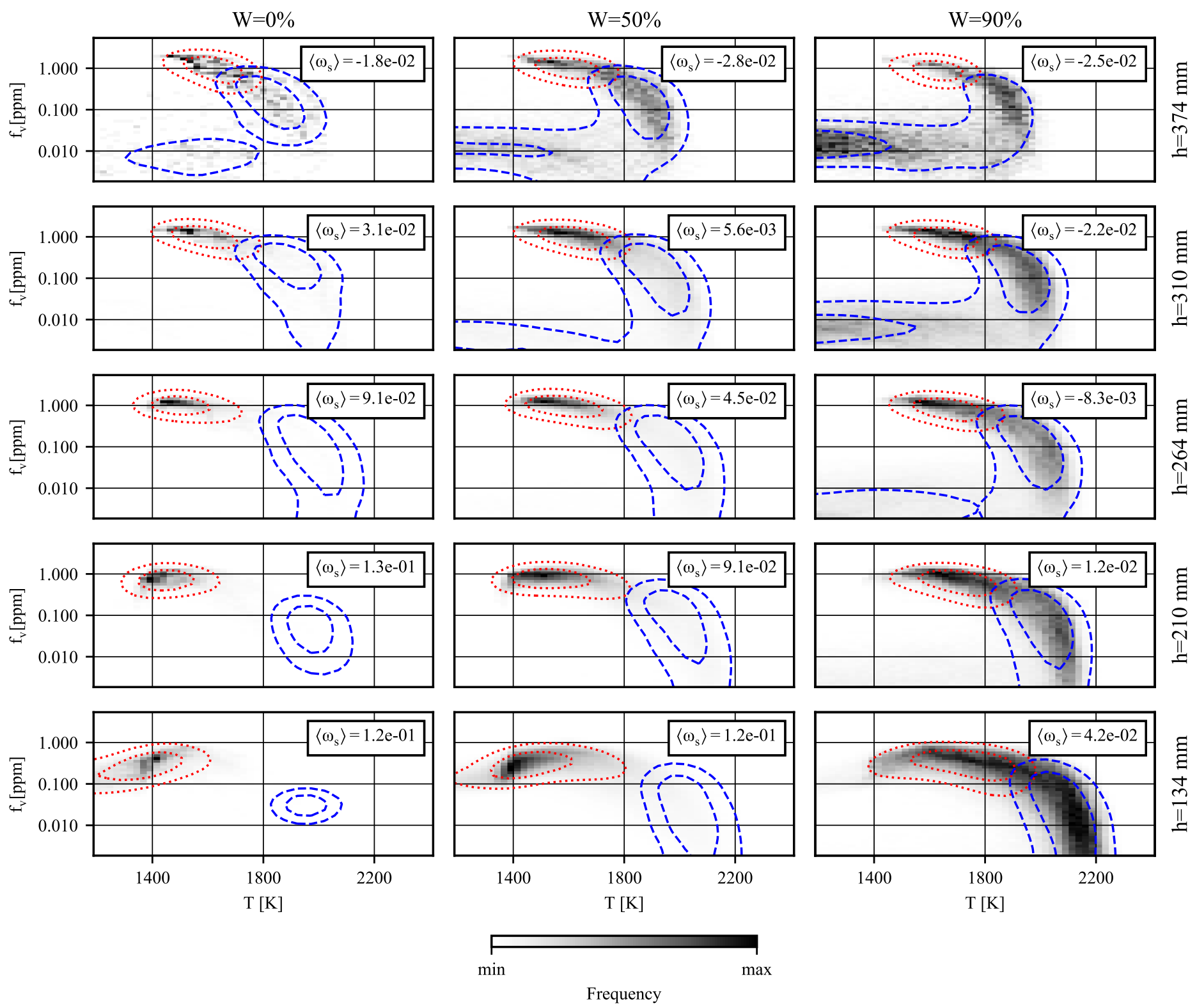

Figure 9: Joint histograms of event probability depending on volume weighted temperature $\mathrm{T}$ and soot volume fraction $f_{v}$ at five heights above the burner $(h)$ and three radial locations. - - - lines indicate regions of dominant soot oxidation $\left(\right.$ Frequency $\left.\left.\right|_{\text {ox }}\right), \cdots \cdot$... lines indicate dominant soot growth (Frequency $\left.\left.\right|_{\text {growth }}\right)$. Mean soot source term $\left\langle\omega_{s}\right\rangle$ is in $\mathrm{kg} /\left(\mathrm{m}^{3} \mathrm{~s}\right)$. 

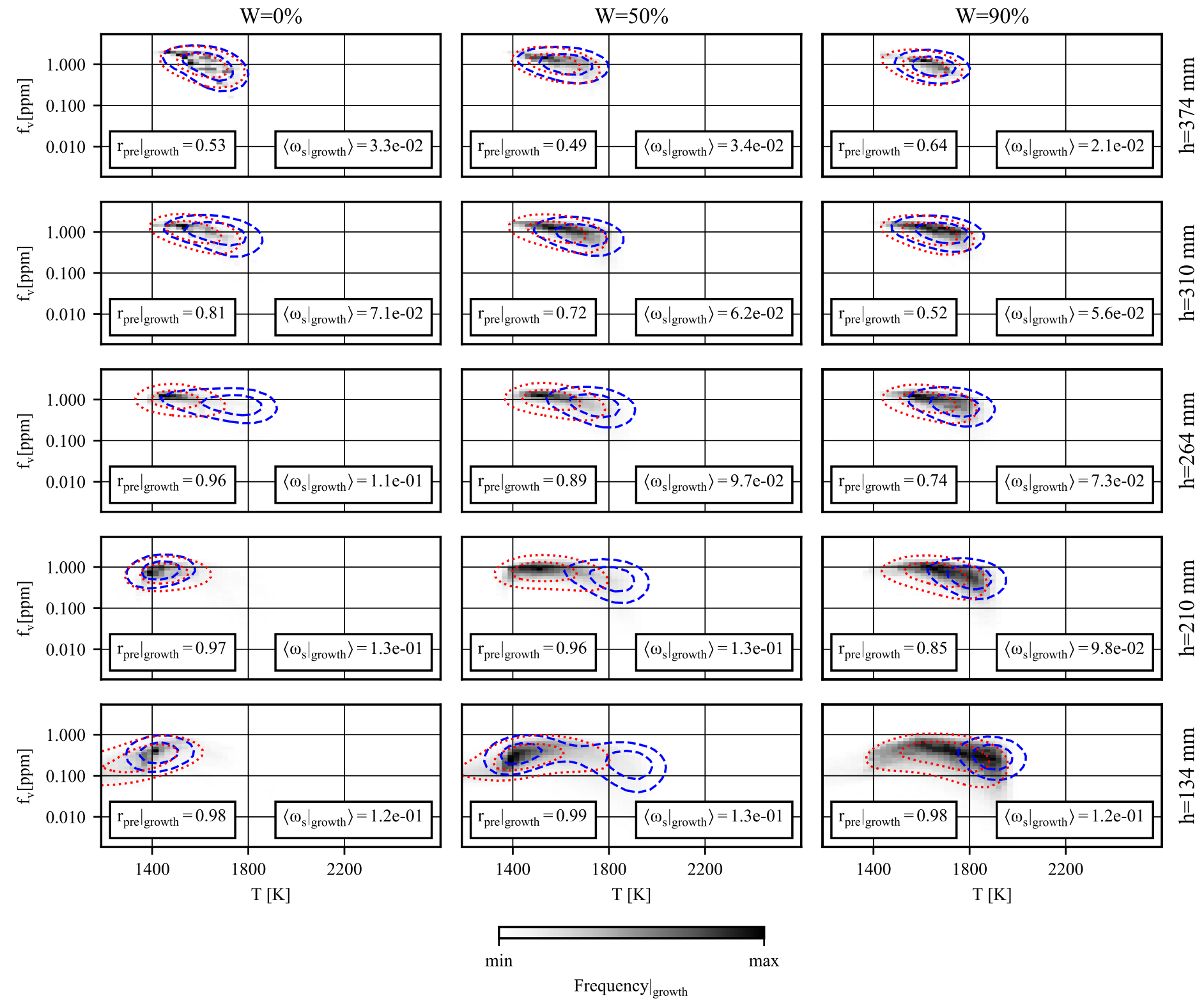

Figure 10: Joint histograms of event probability depending on volume weighted temperature $T$ and soot volume fraction $f_{v}$, conditioned on soot growth, at five heights above the burner $(h)$ and three radial locations. $\ldots . .$. lines indicate statistics further conditioned on the premixed combustion regime (Frequency $\left.\right|_{\text {growth, }}$ pre). - - - lines indicate statistics further conditioned on the non-premixed combustion regime (Frequency $\left.\right|_{\text {growth, dif }}$ ). Mean conditioned soot source term $\left\langle\left.\omega_{s}\right|_{\text {growth }}\right\rangle$ is in $\mathrm{kg} /\left(\mathrm{m}^{3} \mathrm{~s}\right)$. 

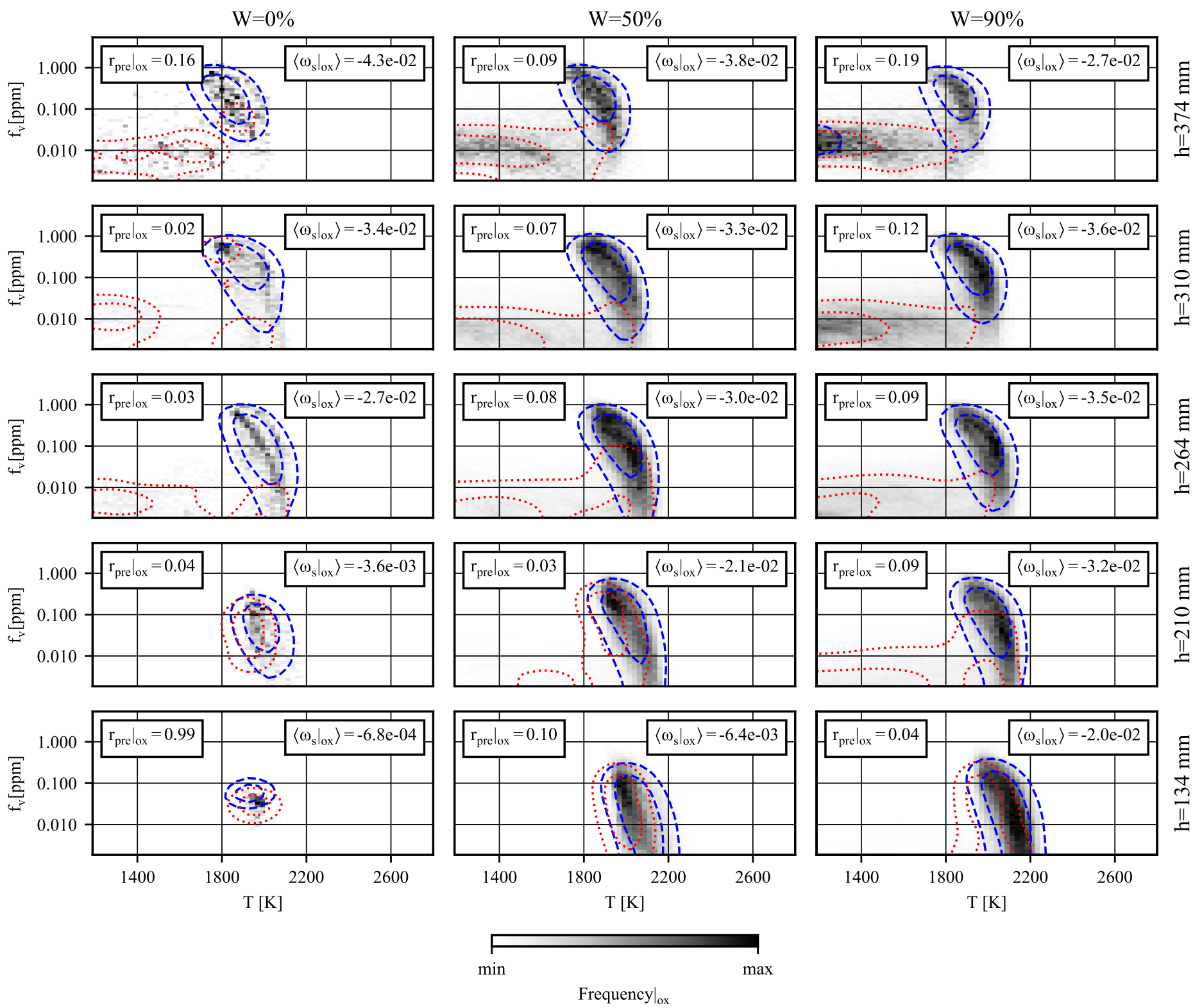

Figure 11: Joint histograms of event probability depending on volume weighted temperature $T$ and soot volume fraction $f_{v}$, conditioned on soot oxidation, at five heights above the burner $(h)$ and three radial locations..... lines indicate statistics further conditioned on the premixed combustion regime (Frequency|ox, pre). - - - lines indicate statistics further conditioned on the non-premixed combustion regime (Frequency $\left.\right|_{\text {ox } \text { dif }}$ ). Mean conditioned soot source term $\left\langle\left.\omega_{s}\right|_{\mathrm{ox}}\right\rangle$ is in $\mathrm{kg} /\left(\mathrm{m}^{3} \mathrm{~s}\right)$. 